\title{
A TRANSFERÊNCIA COMO MEIO DE TRATAMENTO DO OUTRO E RECURSO DE CONTENÇÃO À PASSAGEM AO ATO NA PSICOSE
}

THE TRANSFERENCE AS A WAY TO TREAT THE OTHER AND MEANS OF HOLDING BACK THE PASSAGE TO THE ACT IN PSYCHOSIS

LA TRANSFERENCIA COMO MEDIO DE TRATAMIENTO DEL OTRO Y COMO RECURSO DE
CONTENCIÓN DEL PASAJE AL ACTO EN LA PSICOSIS Mynéia Campos Oliveira Santos* Guilherme Massara Rocha ${ }^{* *}$

\begin{abstract}
RESUMO
Este artigo se propõe a investigar, com base no estudo de um caso clínico, de que modo a manobra da transferência na psicose nos permite apostar em sua eficácia como meio de tratamento do Outro e recurso de contenção à passagem ao ato nessa estrutura. Orientados pela leitura lacaniana, constatamos que, na psicose, o simbólico não opera na negativação do gozo, o que faz com que este retorne sobre o psicótico de forma maciça na figura de um Outro ameaçador. Consequentemente, a passagem ao ato nessa estrutura se configura como uma tentativa de extrair o excesso de gozo no campo do Outro. Diante dessa observação, a manobra da transferência seguiu como orientação o tratamento do Outro para fazer barreira ao transbordamento da pulsão, ou seja, uma modalidade de trabalho que buscou regular o gozo do Outro mediante estratégias criadas pelo que se mostrou possível na particularidade do caso.
\end{abstract}

Palavras-chave: Psicose. Transferência. Tratamento do Outro. Passagem ao ato.

\begin{abstract}
The aim of this article is to investigate, based on a clinical case, the way the transference maneuver in psychosis allows us to rely on its efficacy as a way to treat the Other and means to hold back the passage to the act in this structure. Oriented by the reading of Lacan's writing, we determined that in psychosis the symbolic does not operate in the negativity of the pleasure, which makes it returns over the psychotic subject in a fierce way as a frightening figure of the Other. Consequently, the passage to the act in this
\end{abstract}

Texto recebido em 5 de março de 2016 e aprovado para publicação em 21 de setembro de 2016

* Mestra em Psicologia pela Universidade Federal de Minas Gerais (UFMG), psicóloga no Instituto Raul Soares (Fhemig). E-mail: myneiacampos@yahoo.com.br.

** Doutor em Filosofia pela USP, professor no Departamento de Psicologia da UFMG, psicanalista. E-mail: massaragr@gmail.com. 
structure is pictured as an attempt to withdraw the excess of enjoyment from the Other's field. In face of this observation, the transference maneuver took as guideline the treatment of the Other to block the overflow of the pulsion; in other words, a work modality that meant to regulate the enjoyment of the Other through strategies created by what was possible in this case.

Keywords: Psychosis. Transference. Other's treatment. Passage to the act.

\section{RESUMEN}

Este artículo propone investigar, a partir del estudio de un caso clínico, de qué manera la transferencia en la psicosis nos permite apostar en su eficacia como medio de tratamiento del Otro, y como recurso de contención de pasar al acto en esa estructura. Guiados por la lectura Lacaniana, vimos que en la psicosis lo simbólico no opera en la negativización del goce, lo que hace que este vuelva sobre el psicótico de forma masiva en la figura de un Otro amenazador. Consecuentemente, el pasaje al acto en esa estructura se configura como una tentativa de extraer el exceso de goce en el campo del Otro. Frente a esa observación, la maniobra de transferencia continuó como orientación en el tratamiento del Otro para levantar una barrera en el transbordo de la pulsión, o sea, una modalidad de trabajo que buscó regular el goce del Otro a través de las estrategias creadas, como fue posible observar en la particularidad del caso.

Palabras clave: Psicosis. Transferencia. Tratamiento del Otro. Pasaje al acto.

\section{INTRODUÇÃO}

$\mathrm{N}$

o cotidiano de nossa prática no hospital psiquiátrico, temos nos deparado intensamente com a presença de casos de passagens ao ato graves que têm mudado a rotina da instituição, exigindo avanços teórico-clínicos que nos orientem diante dos impasses surgidos, principalmente quando estes acarretam sérios danos para o sujeito e para as pessoas de seu convívio.

Nosso tema de trabalho, referente à construção de um tratamento possível das passagens ao ato na psicose, surgiu especificamente das indagaçóes suscitadas durante o tratamento de um paciente esquizofrênico, cuja internação no hospital teve duração de 1 ano e 4 meses, uma longa permanência, justificada pela relatividade de sua resposta às intervenções terapêuticas propostas.

Paulo, como o nomeamos, apresentava histórico de várias internações psiquiátricas, marcadas por longos períodos de contenção física, refratariedade ao uso das medicações e, por fim, a indicação do Centro de Atenção Psicossocial (CAPS) de seu Município, de que se esgotaram os recursos extra-hospitalares de 
tratamento. Foram solicitadas ao hospital novas sessóes de eletroconvulsoterapia (ECT) e avaliação para psicocirurgia.

O paciente foi encaminhado à instituição devido à intensidade de suas passagens ao ato, que se mostravam repentinas, repetitivas e sem motivação aparente. Paulo se mostrava persecutório com vizinhos, profissionais de saúde e familiares, agredindo-os fisicamente e se envolvendo em conflitos que o colocavam em risco, assim como as pessoas próximas.

A gravidade de seu quadro bem como a diversidade dos fenômenos exibidos impressionavam. Paulo se atirava sobre os outros pacientes e equipe de enfermagem de maneira intempestiva, quebrava vidros, jogava coisas no chão, delirava, queixava-se de vômitos e outras manifestaçōes no corpo, machucava-se durante seus rompantes, sempre acusando os outros de maus-tratos e difamações.

Essa variedade na sintomatologia legitimou diferentes propostas diagnósticas elaboradas pela Psiquiatria, assim como a aplicação de diferentes técnicas de intervenção, objetivando a cessação de seus sintomas. Mas, apesar de toda medicação testada e de tantas sessões de ECT, por que o paciente não melhorava? ${ }^{1}$ $\mathrm{O}$ que se encontrava em causa em suas passagens ao ato? Como operar com esse paciente de forma a construir um tratamento que o incluísse de alguma forma?

Dessa maneira, tomando como referência a construção do caso clínico como método de pesquisa em psicanálise, procuramos reunir as indicações subjetivas durante o tratamento de Paulo com sua psicóloga que apontassem para o estabelecimento da transferência e, a partir dessa evidência, recolher os efeitos que se mostraram possíveis sobre suas passagens ao ato e sobre a relação estabelecida com o Outro, tendo como alicerce a manobra da transferência.

A construção do caso clínico implica um esvaziamento prévio de saber por parte do profissional e o acompanhamento cuidadoso dos passos do paciente, colocando-o a trabalho e registrando seus movimentos para que, assim, estejamos atentos para quando algo de novo advir (Viganò, 1999).

A orientação clínica baseada no vazio de saber que, por sua vez, não corresponde a um vazio de assistência (Viganò, 1999), é condição necessária para que a demanda do sujeito emerja, proporcionando a oportunidade para que ele se interrogue sobre aquilo que o acomete. No momento da construção, nós nos colocamos no lugar de testemunha do trabalho do paciente, em que podemos aprender sobre seu modo de gozo e assim orientar um tratamento no qual ele esteja minimamente implicado. Trata-se de um método que permite articular

\footnotetext{
1 Foram realizadas, ao todo, 56 sessões de ECT e administradas as seguintes medicações, utilizadas em diferentes combinaçōes e dosagens ao longo de seu tratamento: antipsicóticos (Clorpromazina, Tioridazina, Trifluoperazina, Haloperidol, Risperidona, Olanzapina, Quetiapina, Clozapina); anticonvulsivantes e estabilizadores do humor (Carbamazepina, Ácido Valpróico, Lamotrigina); benzodiazepínicos (Clonazepam); outros (Biperideno).
} 
o saber adquirido com o que de novidade o caso nos apresenta, sem deixar de marcar o que de singular ele destaca como exceção, trajeto metodológico que Freud percorreu ao longo de toda a sua obra.

Pela construção do caso, portanto, foi possível partir de um primeiro momento em que o paciente é apresentado pelo Outro (seja a instituição psiquiátrica, seja o serviço de saúde mental de sua cidade, seja por seus familiares) como alguém agressivo e sem controle, tomado por reações impulsivas, refratário ao uso das medicações, com resposta limitada às sessões de ECT, em que se cogitou a proposta de psicocirurgia diante dos limites das intervenções; para um segundo momento, em que pudemos interrogar, a partir do acompanhamento do percurso do paciente e da disponibilidade em tolerar algo de intratável no caso, sobre a função que as passagens ao ato exerciam para Paulo e sobre a maneira com que o Outro se configurava nessas circunstâncias, abrindo então para a possibilidade de um tratamento baseado nas indicações apresentadas pelo próprio paciente.

\section{AS ESPECIFICIDADES DA PSICOSE COMO ESTRUTURA CLÍNICA}

"Toda loucura é vivida no registro do sentido" (Lacan, 1946/1998, p. 166). ${ }^{2}$ Essa formulação de Lacan nos evidencia que os fenômenos vivenciados pelo psicótico, a exemplo das alucinações, interpretaçôes e intuições delirantes, mesmo que lhes sejam enigmáticos, concernem à sua pessoa. É o que observamos no caso de Paulo, quando este, apesar de não conseguir dar uma explicação para o que lhe acomete, "Não sei, fia, é coisa de Deus", toma as coisas que acontecem a seu redor como certamente dirigidas a ele.

O que Paulo escutava dos outros, como "o interesse por sua cidade", o que ele via à sua volta, o comportamento das enfermeiras, as pessoas que encontrava pelo caminho e que reconhecia como seus parentes, o olhar dos demais pacientes que "sentiam inveja dele" e queriam "roubar seus planos e lhe fazer mal", todos esses fenômenos apontam para a radicalidade da certeza a partir da qual "o delirante se exime de toda referência real” (Lacan, 1955-1956/2008, p. 94).

O que está em jogo, portanto, não é a confirmação pelo psicótico da veracidade de suas vivências no campo da realidade, mas a emergência de uma significação inabalável que lhe remete diretamente.

O que Lacan (1955-1956) propõe, a partir de seu retorno a Freud, éa restituição do sentido na cadeia dos fenômenos, mas ressalta que o sentido de que se trata não é aquele que supomos compreender. Para o autor, a compreensão é um

2 A primeira data indica o ano de publicação original da obra, e a segunda, a edição consultada pelo autor, a qual somente será pontuada na primeira citação da obra no texto. Nas seguintes, será registrada apenas a data de publicação original. 
termo fugidio, inapreensível. No contato estabelecido com o paciente, devemos partir da ideia do mal-entendido para daí não sobrepormos nossa concepção subjetiva do mundo para explicar o que lhe ocorre. Ele nos adverte dos riscos de reforçarmos o plano imaginário ao permanecermos no registro da compreensão, completando com significaçóes o discurso do psicótico, o que pode provocar desencadeamentos e desestabilizações.

Em contrapartida, a proposta lacaniana se fundamenta na elucidação dos mecanismos constituintes subjacentes aos fenômenos apresentados na psicose, buscando tornar clara sua especificidade como estrutura clínica, tendo como referência a incidência da linguagem e o papel dos registros imaginário, simbólico e real em sua formação.

Essa foi a orientação que seguimos na condução do caso de Paulo, pois, diante de diferentes concepções sobre seu caso, baseadas na variedade de sintomas apresentados, foi imprescindível o resgate dos princípios teórico-clínicos que pudessem fundamentar nossa intervenção.

Segundo Lacan (1957-1958/1998), o que acontece ao sujeito, seja na neurose ou na psicose, depende do que se passa no campo do Outro como lugar do código significante de onde pode ser formulada a questão sobre sua existência. A partir de seus estudos sobre Linguística, o autor depreende que a realidade é estruturada pela presença do significante, visto que somos seres de linguagem e nossa relação com o mundo é mediada pela fala. Dessa forma, ele estabelece que a inscrição do significante Nome do Pai no campo do Outro ou sua rejeição radical acarreta consequências distintas em duas estruturas clínicas, pois é a ação desse significante que ratifica o Outro como sede da lei e estabelece o ordenamento simbólico necessário para que o sujeito se situe no mundo.

Para Lacan (1957-1958), a condição essencial que define a psicose se refere à foraclusão do significante Nome do Pai no campo do Outro e ao fracasso da metáfora paterna para "significantizar" o que acontece ao sujeito em sua relação com a realidade. O Nome do Pai é o significante que entra como mediador na relação do sujeito com o Outro, fazendo operar a castração e a inscrição da falta no campo do Outro.

A ausência dessa operação, da entrada de um terceiro para fazer valer a inscrição da lei, explica a relação que Paulo estabelece com o outro semelhante, preso numa relação em espelho em que imperam os sentimentos de hostilidade e persecutoriedade, sem a mediação necessária que torna possível um distanciamento. 
Da mesma maneira, a foraclusão do significante nos permite apreender o estatuto que o Outro assume na psicose. O Outro nessa estrutura, ao não sofrer os efeitos da promulgação da lei simbólica, permanece associado a uma figura absoluta e consistente, não barrada, Outro do gozo não regulado pela norma fálica e que toma o psicótico como objeto de abuso.

Avançando um pouco mais no ensino de Lacan, tomamos a formalização realizada pelo autor sobre o objeto $a$ no Seminário 10 (Lacan, 1962-1963/2005) para dar prosseguimento à nossa investigação. Na neurose, o campo da realidade se sustenta pela extração do objeto $a$, o que implica em uma perda de gozo quando constituímos a realidade como representação significante.

O objeto $a$ é o produto da operação da linguagem sobre o sujeito e tem como correlato sua divisão. Trata-se da dimensão do corte que separa um resto que não é "significantizável", marcando o sujeito como falta a ser devido à extração de gozo obtida pela inscrição primária de um significante.

O neurótico tem a fantasia como recurso simbólico para velar o real e dar um contorno ao furo estruturante constituído pela extração do objeto $a$ no campo do Outro. Na psicose, em contrapartida, a extração não ocorre, uma vez que não há a incidência do significante necessária para promover a separação entre o gozo e o Outro, inscrevendo, assim, a dimensão da falta. A não extração do objeto apresenta como correlato um excesso de gozo não bordejado pelo simbólico e que retorna no real de forma desvelada (Carvalho, 2014).

Dessa maneira, diante da falta de mediação simbólica para lidar com o gozo desmedido, a passagem ao ato pode se mostrar uma saída viável na psicose como tentativa forçada, pela via do real, de extrair o objeto $a$, de lidar com o gozo insuportável não negativado pela via significante.

No caso de Paulo, podemos antever suas passagens ao ato como uma saída encontrada por ele para lidar com o Outro que, por não ter sofrido os efeitos da castração, mostra-se invasivo e perseguidor, tomando-o como objeto. Seus atos agressivos, repentinos e sem controle, surgem como resposta à intrusão do olhar do Outro que sente inveja dele, quer roubar seus planos e o faz vomitar.

O sofrimento e mal-estar sentidos no corpo apontam para a dimensão "kakoniana" do objeto que não foi extraído e que Paulo atinge "extimamente" no outro semelhante ou no próprio corpo a procura de alívio. Preso na relação especular com o outro e na falta do contorno dado ao próprio corpo que lhe permita distinguir o que é seu e do outro, Paulo agride a si mesmo quando atinge aquele a quem dirige $\mathrm{o}$ ato agressivo, buscando estabelecer algum distanciamento e tratamento ao mal-estar. 
Assim, seus atos, considerados sem motivação, podem ser apreendidos conforme consideramos os elementos próprios à sua estrutura subjetiva. Suas passagens ao ato podem ser lidas como reaçôes ante o embaraço provocado por um mal vivenciado como vindo do Outro gozador e do qual precisava se defender. Entretanto constatamos a pouca efetividade dessa resposta no caso de Paulo como recurso para lidar com o real, pois qualquer sinal advindo do Outro o convocava a reagir uma vez mais pelo ato.

\section{A MANOBRA DA TRANSFERÊNCIA NA PSICOSE}

No texto De uma questão preliminar a todo tratamento possivel da psicose, Lacan (1957-1958) formula a necessidade de localizar a foraclusão e o fracasso da metáfora paterna como fatores essenciais a serem considerados previamente quando se tem por objetivo o tratamento e a manobra da transferência na psicose.

Ao se referenciar no caso Schreber, escrito por Freud (1911/1996), Lacan depreende de sua análise o quão repugnante era para o narcisismo do paciente ocupar uma posição feminina diante do pai, sentimento que foi transferido sobretudo para seu médico Flechsig, por meio do delírio.

Dessa análise, Lacan verifica que o processo de negação dos impulsos pulsionais resulta no que ele denomina de "erotomania divina" (Lacan, 1955-1956, p. 358), em que Schreber é tomado como objeto de gozo de um Deus onipotente que lhe provoca imaginariamente uma série de transformações corporais para usufruto de seu corpo como mulher.

Essa observação, aliada ao raciocínio de Lacan (1957-1958), ao evidenciar que a investigação de Freud sobre Schreber aponta a transferência como fator que precipitou seu desencadeamento, permite-nos tomar a erotomania como uma característica própria à manifestação do fenômeno transferencial na psicose. ${ }^{3}$

Mais à frente em seu ensino, no prefácio elaborado para a edição francesa do livro de Schreber, essa evidência se mostra mais consistente. Aí Lacan afirma, tendo como referência a relação entre Flechsig e Schreber, que o psicótico tende a se colocar diante do clínico na posição de "objeto de uma espécie de erotomania mortificante” (Lacan, 1966/2003, p. 223). Acrescenta ainda que se trata de uma posição introduzida pela lógica do tratamento, ou seja, é inerente à sua estrutura de funcionamento.

\footnotetext{
3 Tanto a erotomania como as ideias persecutórias evocadas na transferência na psicose apontam para a associação que se estabelece entre saber e gozo quando não se pode contar com o Nome do Pai para operar a castração simbólica. No caso Schreber, podemos notar o quão eminente era a posição de Flechsig como figura importante no que tange ao saber sobre o trabalho com as enfermidades mentais. A própria esposa de Schreber o tinha em grande conta por ter tratado seu marido com sucesso durante sua primeira crise. Dessa maneira, a posição de saber ocupada por Flechsig na transferência pode ser apontada como fator que levou à irrupção do quadro delirante de Schreber, marcado pela erotomania e persecutoriedade, em que o paciente se vê preso como objeto de gozo do Outro.
} 
Segundo Maleval (2002), a relação que o psicótico estabelece com o analista, sob a forma da erotomania de transferência, apresenta-se como um fato de estrutura que pode ser depreendido das formulações de Lacan na década de 1950, quando determina os mecanismos específicos da psicose. Nessa estrutura, encontramo-nos no campo da certeza delirante, da falta de referencial simbólico que impede qualquer dialética, em que a significação emerge no real, impondose ao sujeito.

De acordo com Maleval (2002), as formulações de Lacan referentes à desregulação do gozo na psicose propiciam uma nova orientação no que concerne ao seu tratamento. Para o autor, a erotomania mortificante presente nessa estrutura pode ser entendida como consequência de certa inversão dos lugares dos protagonistas que são ocupados no tratamento com neuróticos.

O que podemos antever, ao tomar psicóticos em análise, é que o objeto, não extraído, não se localiza no campo do Outro como na neurose, do lado do analista, mas, pelo contrário, encontra-se do lado do psicótico, sujeito do gozo para quem o analista é visto como aquele que quer gozar dele.

Sobre essa questão, Zenoni (2007) apresenta uma concepção semelhante. Segundo o autor, a transferência na psicose deve ser entendida como um fenômeno de estrutura diferente do que se encontra em jogo na neurose e, como tal, apresenta suas especificidades. Dentre elas se destaca que a não extração do objeto $a$ tem como correlato a inversão do vetor transferencial na psicose.

Dessa forma, observamos que, na neurose, o sujeito se dirige ao campo do Outro a quem supóe possuir o objeto que lhe falta. Nele o neurótico presume um saber, demandando uma resposta acerca de seu ser e sobre seu lugar no desejo do Outro.

Na psicose, em contrapartida, o Outro se impõe visto que o psicótico é tomado como aquele que possui o que lhe falta. "É o sujeito que realiza e encarna o que falta no Outro como gozo. A realidade começa a girar em torno do sujeito, ela se polariza sobre ele" (Zenoni, 2007, p. 6, tradução nossa).

Dito de outra maneira, a inversão do lugar do objeto coloca o psicótico como alvo do interesse e do querer do Outro, o que permite a Zenoni (2007) afirmar que o psicótico responde, de antemão, à transferência do Outro, transferência que o precede de alguma maneira, pois é o Outro quem o procura, persegue-o e quer algo dele.

A não extração do objeto a tem como correlato um gozo desmedido na figura do Outro não barrado que submete o psicótico a seus caprichos. Como consequência, a transferência tende a se manifestar em sua dimensão persecutória 
ou erotômana, ambas posições em que o psicótico é capturado como objeto do Outro.

Ante essa asserção, tanto Maleval (2002) quanto Zenoni (2007) apontam que a particularidade do fenômeno transferencial na psicose exige do analista uma modalidade de presença e intervenção distinta. Diante do Outro absoluto que não sofreu a regulação da norma fálica, propõe-se uma direção do tratamento dirigida para a modulação do gozo desregrado na psicose e um manejo da transferência que procure se opor à imposição do Outro sobre o psicótico.

Como recurso, Zenoni (1991) apresenta a proposta de tratamento do Outro como um modo de agenciamento simbólico que tem por objetivo estabelecer um intervalo entre o sujeito e o Outro, seja por meio da palavra ou de um ato que procure colocar uma barra sobre o Outro excessivo tal como se configura na psicose.

Usando essa estratégia, busca-se tornar o Outro menos consistente assim como se apresenta pelos fenômenos elementares. Trata-se de uma aposta em outra configuração possível de alteridade. Presentificar um outro Outro que não desperte a erotomania e a persecutoriedade na transferência, em que a dimensão do desejo do Outro não se encontre em causa, fazendo enigma para o psicótico.

A ideia de tratamento do Outro pode nos servir de guia em relação ao trabalho com a psicose no cotidiano de nossa prática, assim como uma referência importante no que concerne à manobra da transferência. Sobre essa manobra, fundamental na condução do tratamento, Zenoni (2007) nos recomenda alguns pontos de orientação a serem avaliados no caso a caso.

Como primeiro ponto, o autor propõe que devemos "tratar" a nossa transferência, ou seja, localizar-nos de forma distinta do lugar ocupado pelo Outro na psicose. Para isso, é preciso abdicar da ideia de aplicar ao paciente o projeto que consideramos ser o melhor para ele, colocando-o dessa maneira na posição de objeto de uma intervenção.

Como alternativa, nosso trabalho pode ser dirigido no sentido de procurar esvaziar o Outro em sua dimensão invasiva e ocupar um lugar de endereçamento por meio do qual o psicótico possa estabelecer algum distanciamento e escoamento de gozo.

O segundo ponto refere-se ao lugar da fala. Os equívocos da linguagem próprios à ambiguidade do significante fazem com que a fala em si aponte para a dimensão do além do que é dito ou enunciado e para além do que é mostrado. A fala evoca o que pode estar subentendido no discurso e é essa ambiguidade que devemos evitar convocar. 
Trata-se de não apontar para uma significação oculta na fala do psicótico e de não interpretar seus dizeres, indicando um sentido outro que lhe escape. Caso não sigamos essas diretrizes, corremos o risco de assumir para ele um lugar de mestria e domínio, despertando reações persecutórias ou de submissão como objeto de abuso do Outro.

Aliada a essa questão de refrear a ambiguidade da fala, Zenoni (2007) acrescenta uma terceira indicação: evitar reforçar o registro do sentido, o que pode remeter a uma cadeia infinita de busca por significações, sem ponto de interrupção.

Como consequência, nossa prática deve procurar relativizar a importância terapêutica dada à produção de sentido e do se expressar em palavras, pois a palavra também pode funcionar como vetor de gozo. O autor vê com cautela a perspectiva que institui a fala e a construção de sentido como uma ferramenta que pode anular o gozo. Pelo contrário, isso pode reforçá-lo, presentificando-o uma vez mais.

Essa advertência nos serviu de alerta durante a condução do tratamento de Paulo. Entendemos que não foi nessa direção que procuramos trabalhar, mas sim utilizando-nos da palavra para introduzir uma dúvida, promover alguma vacilação da certeza delirante. Apostamos na

Possibilidade de introdução de pontuações e pontos de interrupção no trabalho de deciframento efetuado pelo sujeito. Estes visam a aliviá-lo da obrigaçáo ilimitada de entender à qual ele pode estar submetido. Trata-se então de introduzir cortes e espaçamentos em seu trabalho incessante de interpretação dos signos para que este não chegue a uma conclusão no real através de uma passagem ao ato (Zenoni, 2007, p. 17, tradução nossa).

Em muitos momentos, o silêncio pode se mostrar, em certa medida, uma boa estratégia. Porém não se trata de impor padrões do que deve ser aplicado numa intervenção. Essas são indicações das quais o analista deve estar advertido para evitar ocupar um lugar na transferência que inviabilize o tratamento.

O nível de silêncio e o uso que cada sujeito faz da palavra do analista deve ser verificado no particular de cada caso, a partir de um saber a ser construído no trabalho com cada um. A proposta é uma certa disciplina na fala a partir do que se mostra possível abordar durante o percurso do tratamento (Zenoni, 2007).

De posse dessas orientações, passaremos à condução do caso de Paulo, dando enfoque às modulações possíveis da transferência e às funções exercidas por sua psicóloga que possibilitaram o engajamento no tratamento. 


\section{CASO PAUlO: A CONSTRUÇÃO DE UM TRATAMENTO POSSÍVEL}

As primeiras impressões recolhidas da observação de Paulo permitiram a elaboração de um cálculo que pudesse orientar nossa ação. Para articulá-lo, a determinação do diagnóstico do discurso, ou seja, a localização da maneira com que o sujeito se situa diante do Outro (Viganò, 1999) foi imprescindível.

De acordo com o que percebíamos, sua agitação, desconfiança e atos agressivos apontavam para algo de insuportável em sua relação com o Outro, principalmente na vertente do olhar, que se mostrava para ele como uma figura hostil e ameaçadora, mantendo-o em estado de alerta constante.

Da mesma maneira, a posição da equipe diante de Paulo, ao responder com técnicas contentivas com o intuito de protegê-lo, parecia reforçar ainda mais suas queixas de que estavam "judiando" dele e lhe fazendo mal.

Diante disso, foi necessário se distanciar desse Outro tal como se revelava para Paulo, e, para tanto, seguimos sua primeira indicação. Notamos que Paulo abordava as pessoas no corredor da enfermaria para falar de seus "problemas" e que essas pessoas se esquivavam ou o escutavam por pouco tempo. Dessa forma, nós nos colocamos à disposição para escutá-lo por meio do acolhimento de suas queixas e das vivências ofensivas das quais procurava dizer.

Nesse momento, localizamos a primeira função que ocupamos para o paciente, que permitiu a abertura para a transferência: o lugar de testemunha, fundamentado no interesse de escuta atenta e mais silenciosa e numa presença que possibilitou um primeiro endereçamento.

De acordo com o dicionário, uma das definições de testemunha refere-se à "Pessoa que assiste a certos atos para os tornar autênticos e valiosos" (Trevisan, 2012), o que nos remete, no caso de Paulo, à busca pela legitimidade de seu sofrimento nas reiteradas vezes em que passou a procurar sua psicóloga, inclusive pedindo-a que ficasse a seu lado nos momentos de contenção. Nessa posição, o analista não visa a provocar alguma modificação do sujeito, mas sustenta sua presença silenciosa para autenticar as vivências e produções delirantes do psicótico (Beneti, 1996).

Dessa maneira, acreditamos que o lugar de testemunha se mostrou possível visto que assumimos o esvaziamento no campo do saber e do querer, não dirigindo nenhuma demanda ao paciente, deixando a seu cargo o saber sobre sua condição.

Outra observação que nos auxiliou a estabelecer um cálculo de ação relacionase ao ambiente da enfermaria. Notamos que o ambiente tumultuado, repleto de 
pacientes em crise, intensificava sua agitação, fazendo-o reagir diante da invasão do olhar do Outro através das passagens ao ato.

Mediante essa constatação, convidamos Paulo para passear pelos demais espaços do hospital, apostando que, dessa maneira, poderíamos, de alguma forma, diminuir a consistência do Outro que o ameaçava.

De acordo com Zenoni (2000a), não há uma receita que possa ditar os caminhos de intervenção no campo das psicoses, mas se mostra importante nos questionarmos sobre a função que a passagem ao ato ocupa para cada sujeito e, a partir daí, ver se é possível transpor essa função para fora do corpo, para além do outro semelhante

A proposta dos "passeios", como o próprio paciente os denominava, pôde ser entendida como a possibilidade de promover um deslocamento, ou melhor, introduzir algo novo que pudesse romper com esse circuito. Mesmo ainda muito atordoado e persecutório com os demais, foi feita a oferta.

Em um dos primeiros passeios realizados, aconteceu um fato interessante que, a nosso ver, serviu como um marco importante para estabelecer uma diferença para o paciente no que se refere ao lugar que sua psicóloga poderia ocupar para ele. Após uma tentativa frustrada de falar com os pais e com a polícia pelo orelhão, Paulo desfere a ela um leve tapa nas costas.

Desse ato não ocorreu nenhum revide, como talvez ele pudesse esperar, nem uma reação de fuga ou rejeição. Em contrapartida, Paulo foi questionado sobre o que aquilo queria dizer, seguindo sua resposta: "Ah, mas você não faz nada direito, aí eu fiquei nervoso". Como contragolpe, ao paciente é dito que ele poderia falar sobre isso, pois podia ser escutado, não sendo mais necessário que aquilo se repetisse.

De fato, não se repetiu. $\mathrm{O}$ ato de sua psicóloga, naquele momento, pôde mostrar que ela poderia permanecer a seu lado sem constituir uma ameaça, apontando para outro regime de tratamento do gozo para além daquele ao qual estava engajado.

Para Zenoni (2000b), a manobra na transferência na psicose refere-se à presentificação de um Outro barrado, marcado pela falta, em contraposição ao Outro onipotente, que subjuga o psicótico à sua vontade. Não se trata de assumir uma posição paterna ao considerar que nós é que introduzimos a lei, mas de nos colocarmos, nós mesmos, como técnicos, como também subordinados à lei que está posta para todos.

Dessa maneira, contemplamos os passeios como uma estratégia de grande valor que, em seu transcorrer, permitiu que se engendrasse o tratamento do Outro, 
tornando a instituição um espaço mais habitável e terapêutico. Paulo passou a conversar com as pessoas nos corredores e jardins do hospital, abordando-as espontaneamente, sem reagir do modo intempestivo como vinha se apresentando até então.

Não obstante constatamos que sua circulação pelos espaços coletivos do hospital, fora das enfermarias, surtiu efeitos positivos na própria instituição. De um paciente que despertava medo diante da imprevisibilidade de seus atos, para uma pessoa com quem se mostrava possível conversar, oferecer um café ou o jornal do dia e discutir sobre assuntos do cotidiano.

Constatamos que a abertura para conversar sobre outros assuntos relativos a seu dia a dia, para além de seu tratamento, favoreceu a instauração da transferência. Isso porque notamos o quão desconfiado e irritado Paulo ficava quando questionado em suas queixas e em sua implicação nas agressões que dirigia aos outros, o que se apresentava como mais uma ocasião que precipitava seus atos.

Como contrapartida, passamos a conversar sobre seus CDs e músicos preferidos, sobre sua rotina na cidade do interior de Minas, dos trabalhos que já exerceu e das coisas que gostava de fazer. Acreditamos que, ao seguir esse caminho, operamos a manobra da transferência no sentido da "trivialização", termo elaborado por Miller ${ }^{4}$ e citado por Beneti (2005) como uma forma de modulação do gozo.

Falar de "outras coisas", de assuntos triviais e corriqueiros permite afastar a dimensão do Outro hostil na forma com que se passa no discurso do psicótico por meio das ideias delirantes, dificultando, dessa maneira, as precipitações de sentido que podem desembocar em uma passagem ao ato.

Pelas conversas, o que se encontra em foco não é a elaboração do dizer do paciente e sim poder estabelecer um "semblante de diálogo" (Ferreira \& Trópia, 2011, p. 126) a partir do qual podemos recolher elementos que possam orientar a condução do tratamento.

Por conseguinte, a trivialização da transferência se constitui como uma manobra não interpretativa que se contrapóe ao movimento do delírio que, conforme esclarece Beneti (2005), mostra-se um trabalho solitário que raramente faz laço e não proporciona a separação do psicótico do Outro gozador.

Associada à trivialização da transferência, Beneti (1996) apresenta a proposta de estabelecimento do "vínculo frouxo", manejo da transferência feito pelo analista, buscando manter um intervalo no eixo imaginário, de forma que ele

4 De acordo com Ferreira e Trópia (2011), Miller fala de trivialização da transferência em uma de suas conferências em Milão, no ano de 1999. Trata-se de texto inédito, indisponível para consulta. 
não seja colocado no lugar do outro semelhante numa relação especular. Essa proposta envolve a flexibilização e espaçamento entre os encontros, em que se evitam interpretações e aconselhamentos, mantendo uma presença que não se mostre ameaçadora, com a qual o paciente possa contar para lidar com o Outro.

Pois bem, ao identificarmos os passeios como um recurso inédito no caso que proporcionou que outras invençôes para o tratamento do Outro se mostrassem possíveis, vislumbramos outra função do analista na manobra da transferência que ganhou contornos ao longo dos passeios: a função do secretário do alienado.

Trata-se de fazer-se de destinatário dos sinais que nos são endereçados e de participar junto ao psicótico, mediante o trabalho de construção, a elaboração de soluções possíveis para tratar o real (Zenoni, 2000a).

Entendemos que conforme Paulo permitia que sua psicóloga circulasse com ele pelo hospital, introduzisse alguma questão em meio às suas conversas e o acompanhasse nas atividades em que se propunha a fazer, a função de secretariado foi se mostrando viável.

A seu pedido, sua psicóloga levava revistas, gibis, DVDs de suas bandas prediletas, material para desenho, responsabilizando-se pelo cuidado de seus objetos. A partir das conversas durante os passeios, recolhia pequenos fragmentos de sua história, que surgiam em meio às suas queixas e ideias persecutórias, para deles recompor alguma narrativa subjetiva.

Seguia junto a ele, tomando a frente nos momentos em que o interesse do Outro parecia ganhar muita consistência, então o convidando a continuar a andar ou utilizando-se da palavra para estabelecer algum corte, um desvio que pudesse esvaziar a dimensão do sentido.

Por sua vez, o uso do humor se mostrou um artifício interessante para arrefecer a persecutoriedade do Outro, em que nos pareceu possível deslocar a importância ou a pregnância da presentificação do objeto, como quando Paulo se sentiu confrontado e desconfiado diante de outro paciente, dizendo que ele é "metido com seus óculos escuros".

Nesse instante, a intervenção "Uai, não sabia que você não gostava de óculos" retirou o foco do objeto olhar que encarnava o gozo, transferindo-o para um objeto qualquer, inoperante: os óculos. "É, é bobagem mesmo", como consentiu Paulo.

Essa ação nos remete a Freud (1927/1996), quando traça um pequeno comentário sobre o tratamento das crises paranoicas. Para o autor, em determinado momento do curso da doença, as ideias de perseguição receberiam elevado grau de investimento que as tornariam dominantes, precipitando as crises. 
Diante disso, o tratamento de tais crises não deve se dirigir para a correção ou suspensão das ideias delirantes, mas, antes, precisa fundamentar-se na retirada delas do investimento que lhes foi outorgado, promovendo o deslocamento da energia psíquica.

Esse nos parece o efeito recolhido desse tipo de intervenção junto a Paulo, que lhe permitia rir e se desvencilhar de situações que poderiam gerar conflito. De alguma maneira, o humor produz um efeito no discurso, desviando a ênfase colocada no significante sobre o qual se concentra o gozo, dispersando-o.

Outro momento que nos serve de exemplo se refere à ocasião em que o porteiro do hospital fez perguntas a Paulo sobre sua cidade, enfatizando a abundância na produção dos pequis de lá. O paciente começou a ficar desconfiado diante das perguntas, o que exigiu uma intervenção sutil, uma certa banalização do discurso do Outro para tranquilizá-lo: "Mas sua cidade não é conhecida como a terra dos pequis?". "É verdade, ela é mesmo conhecida por muitas pessoas", ele responde, rindo.

O objetivo que buscamos, portanto, não é a anulação do gozo, mas a busca por uma outra forma de nomeá-lo e de dar tratamento àquilo que se apossa do paciente, pensando estratégias que se mostrem menos lesivas do que suas passagens ao ato (Zenoni, 2007).

A função de secretariado exige disposição para aprender com o paciente as coordenadas necessárias à manobra da transferência, para extrair dos erros um ensino. Por vezes, Paulo indagava sobre o motivo de tantas perguntas ou do interesse por seus CDs; disse, uma vez, à sua psicóloga que ela estava "falando igual médico", alegando que as pessoas têm suas diferenças.

Nesses momentos, era preciso retificar, avaliar a posição ocupada, para que o tratamento pudesse continuar. Afirmar o interesse sim, mas não para gozar dele. Pelo contrário, reforçar a escuta atenta e o interesse em auxiliá-lo: "Talvez falar sobre sua vida possa ajudar em seu tratamento".

Houve ocasiões em que supomos, por parte de Paulo, uma checagem em relação às intenções de sua psicóloga para com ele. Certa vez, perguntou: "Doutora, a senhora é a fim de mim? [ . . .] porque a senhora é a única que passeia comigo".

Diferentemente de um princípio de erotização que poderíamos cogitar, ao nosso ver, trata-se da possibilidade de verificação do estatuto do Outro encarnado na ligação com sua psicóloga. Faria ela parte desse Outro que quer abusar dele e tomá-lo como objeto de gozo? Ante o enigma sobre o desejo do Outro, coube uma resposta esvaziada e a sinalização de um tratamento possível 
sob transferência: "Não, mas entendo que os passeios estão lhe fazendo bem".

Era frequente que Paulo se dirigisse a ela para questionar a intenção das pessoas com quem havia acabado de falar, mostrando-se persecutório e receoso. Diante de sua dificuldade estrutural para compartilhar o discurso comum, era como se ele se servisse de sua psicóloga como uma tradutora ou intérprete dos gestos e pretensões do Outro. Como resposta, não se tratava de dar um significado à postura do Outro, mas de uma intervenção que visasse a diminuir sua consistência, um acolhimento que pudesse trazer algum efeito de apaziguamento.

Mediante esse recurso, Paulo permitia a aproximação das outras pessoas, inclusive se arriscava a procurá-las voluntariamente para conversar e falar sobre "seus sofrimentos". Nos momentos mais difíceis, em que o barulho e a aglomeração de pessoas o incomodavam, recorria à psicóloga para solicitar ajuda: "Vamos embora daqui, doutora, estou com vontade de bater nas pessoas".

Podemos refletir se por essa mediação sua psicóloga cumpriria sua função como um tipo de anteparo, estabelecendo um intervalo no qual antes prevalecia a relação imaginária com o outro semelhante em que se precipitavam suas passagens ao ato.

Da mesma maneira, essa mediação tornava a relação com o Outro mais tolerável, permitindo que Paulo pudesse construir um distanciamento e tratamento do gozo por meio da transferência. Pelo estabelecimento desse vínculo, sua implicação pôde ser colocada em questão, como no caso em que saiu à rua para comprar revistas em quadrinhos e, de repente, sentiu-se invadido, alegando que sentia vontade de pular na frente dos carros.

Nessa e em outras situaçôes, era-lhe perguntado se seria possível ir até a banca ou se ele preferia voltar; ou quando dizia, durante as oficinas, que sentia vontade de bater nas pessoas, questionava-o se daria para terminar a atividade ou se ele preferia interrompê-la.

De início, essa ponderação não se mostrava possível, mas foi ganhando força ao longo do tratamento, permitindo que Paulo se deslocasse da posição de assujeitamento ao Outro a qual ocupava e, assim, pudesse fazer escolhas que lhe permitiam transitar nos espaços coletivos.

Segundo Zenoni (2007), na falta de uma referência interna devido aos efeitos da foraclusão, o psicótico pode encontrar no analista "uma espécie de marco simbólico externo" (p. 18, tradução nossa), desde que se diferencie do lugar do Outro que quer submetê-lo. Por conseguinte, o autor acrescenta que a manobra da transferência consiste num modo de presença em que o psicótico possa se servir do analista como um instrumento, seja na posição de testemunha, 
secretário ou algum outro equivalente, instrumento com o qual o psicótico possa contar sem despertar reações persecutórias. Essa foi a orientação que seguimos ao nos colocarmos à disposição de Paulo para auxiliá-lo no tratamento do Outro.

De forma progressiva e a seu tempo, Paulo foi construindo uma maneira para lidar com o mal-estar no corpo e a invasão de gozo por meio dos passeios, pois, como dizia, ficar na enfermaria o deixava "cansado e nervoso", o que o fazia solicitar àqueles profissionais responsáveis por seu cuidado que saíssem com ele para passear, "ver as árvores e os carros lá fora".

Sem dúvida, os passeios se mostraram um dos principais recursos do tratamento, ao possibilitar o estabelecimento da transferência e servir de contexto para que se engendrasse uma outra alteridade para o paciente, um outro Outro que não se apresentasse tão ameaçador, favorecendo a invenção de saídas para seus impasses.

Durante o desenrolar do tratamento, acompanhamos seu percurso e recolhemos seus efeitos: de um primeiro momento, em que suas ideias persecutórias se precipitavam em um átimo em seus atos agressivos, partindo então para a construção de um intervalo através do qual a palavra passou a operar, fosse por meio da intervenção de sua psicóloga ou como um recurso que começou a funcionar para o próprio paciente.

Esse recurso foi ganhando mais efetividade, e antevemos paulatinamente a introdução do falar no lugar do agir, como podemos perceber nas próprias palavras do paciente: "Antes eu agia sem pensar, mas agora penso antes de agir errado". Do mesmo modo, Paulo passou a dizer que "prefere conversar em vez de brigar" ou, quando se sentia ameaçado, pedia para poder sair de perto, antecipando uma provável ocasião de conflito.

Paulo chegou a reconhecer que tinha parte nas querelas em que se envolvia com a equipe e outros pacientes, afirmando que, por vezes, "provocava". Tomava isso como desígnios dos quais desconhecia: "Mas acontece que eu agrido mesmo, não sei o que acontece, Deus é que deve saber".

Entretanto, pensamos que o tratamento do Outro e o distanciamento e intervalo que se pôde estabelecer entre este e Paulo possibilitou que algo do sujeito pudesse emergir, deslocando-o do lugar de objeto.

Como consequência, observamos que Paulo começou a localizar suas dificuldades, criando estratégias para lidar com elas. Não só pedia ajuda para se afastar dos outros quando antevia a possibilidade de agressão, como passou a dizer, ao longo do tratamento, que conseguia permanecer nos espaços de convivência, mesmo quando sentia vontade de bater nas pessoas. 
Da mesma forma, pudemos presenciar situaçōes em que Paulo, de maneira repentina, dirigia-se a alguns pacientes, mas, dessa vez, para poder lhes pedir desculpas por lhes ter agredido ou provocado em outros momentos, o que proporcionou uma maior aceitação sua por parte dos demais.

Por conseguinte, notamos também que Paulo pôde prescindir da presença de sua psicóloga em diferentes situações, aceitando, ao longo do tratamento, a aproximação de outros profissionais e estagiários para fazer o que gosta: "Passear e conversar".

Por fim, concluímos que os efeitos terapêuticos recolhidos do caso foram resultado do resgate da dimensão clínica na prática com a psicose, da aposta na palavra e no desejo de trabalho e, acima de tudo, da disponibilidade para se colocar a serviço do paciente, auxiliando-o nas saídas que para ele se mostraram possíveis para tratar o gozo.

Dos pressupostos gerais que reunimos e que definem as características da psicose, assim como a maneira com que a transferência e as passagens ao ato se manifestam nessa estrutura, pudemos extrair os elementos que permitiram construir as particularidades do caso, corroborando nossa hipótese de que a manobra da transferência pode servir como meio de tratamento do Outro e recurso de contenção à passagem ao ato na psicose. 


\section{REFERENNCIAS}

Beneti, A. (1996). Interpretação na psicose ou manobras da transferência? Opção Lacaniana, 15, 89-95.

Beneti, A. (2005). Do discurso do analista ao nó borromeano: contra a metáfora delirante. Opção Lacaniana, 3, 1-17. Recuperado a partir de http://www. opcaolacaniana.com.br/antigos/n3/textod.asp\#

Carvalho, F. Z. F. (2014, janeiro-junho). A passagem ao ato como resposta do real. Almanaque on-line - Revista eletrônica do IPSM-MG. 14, 1-12. Recuperado a partir de http://www.institutopsicanalisemg.com.br/psicanalise/ almanaque/14/textos/Almanaque14FredericoFeu.pdf

Ferreira, C. M. R. \& Trópia, M. R. A. B (2011). O escriturário das suplências. Curinga - versão online, 14, 124-128. Recuperado a partir de http:// minascomlacan.com.br/wp-content/uploads/2015/02/curinga-14-pdf.pdf

Freud, S. (1911). Notas psicanalíticas sobre um relato autobiográfico de um caso de Paranoia (Dementia Paranoides). In J. Salomão (Trad.), Edição standard brasileira das obras completas de Sigmund Freud (Vol. 12, pp. 15-89). Rio de Janeiro: Imago, 1996. (Trabalho original publicado em 1911).

Freud, S. (1927). O humor. In J. Salomão (Trad.), Edição standard das obras psicológicas completas de Sigmund Freud (Vol. 21, pp. 163-169). Rio de Janeiro: Imago, 1996. (Publicado originalmente em 1927).

Lacan, J. (1946). Formulações sobre a causalidade psíquica. In V. Ribeiro (Trad.), Escritos. (pp. 152-194). Rio de Janeiro: Jorge Zahar, 1998. (Publicado originalmente em 1946).

Lacan, J. (1955-1956). O Seminário, livro 3: as psicoses (2a ed.). Rio de Janeiro: Jorge Zahar, 2008. (Trabalho original proferido em 1955-1956).

Lacan, J. (1957-1958). De uma questão preliminar a todo tratamento possível da psicose. In V. Ribeiro (Trad.), Escritos. (pp. 537-590). Rio de Janeiro: Jorge Zahar, 1998. (Publicado originalmente em 1957-1958).

Lacan, J. (1962-1963). O Seminário, livro 10: a angústia. V. Ribeiro (Trad.). Rio de Janeiro: Jorge Zahar, 2005. (Publicado originalmente em 1962-1963).

Lacan, J. (1966). Apresentação das Memórias de um doente dos nervos. In V. Ribeiro (Trad.), Outros escritos. (pp. 219-223). Rio de Janeiro: Jorge Zahar, 2003. (Publicado originalmente em 1966). 
Maleval, J.-C. (2002). La forclusión del Nombre del Padre: el concepto y su clínica. Buenos Aires: Paidós.

Trevisan, R. (Org.). (2012). Testemunha. In Michaelis moderno dicionário online da língua portuguesa. São Paulo: Melhoramentos. Recuperado a partir de http:// michaelis.uol.com.br/moderno/portugues/index.php?lingua=portuguesportugues\&palavra=testemunha

Viganò, C. (1999). A construção do caso clínico em saúde mental. Curinga, 13, 50-59.

Zenoni, A. (1991). “Traitement” de l'Autre. Préliminaire, 3, 101-112.

Zenoni, A. (2000a). A psicose fora do desencadeamento. Abrecampos: Psicanálise e instituição: a segunda clínica de Lacan, 1, 51-69.

Zenoni, A. (2000b). Qual instituição para o sujeito psicótico? Abrecampos: Psicanálise e instituição: a segunda clínica de Lacan, 1, 12-31.

Zenoni, A. (2007, janeiro-abril). Comment s'orienter dans le transfert. CliniCaps - Impasses da Clínica, 1. Recuperado a partir de http://www.clinicaps.com.br/ clinicaps_revista_01_art_01.html 